\title{
Associations of exposure to secondhand smoke with hypertension risk and blood pressure values in adults
}

\author{
Qi Zhang ${ }^{1+}$, Guowei Zeng ${ }^{1+}$, Xiaowei Wang ${ }^{2}$ and Kai-Hong $\mathrm{Wu}^{1 *}$
}

\begin{abstract}
Background: The effects of environmental chemical exposure on blood pressure (BP) have been confirmed, but the association between exposure to secondhand smoke (SHS) and hypertension risk and BP in the general population remains unknown.
\end{abstract}

Methods: Cross-sectional associations between SHS exposure and hypertension risk and BP values were evaluated using data for subjects who participated in the National Health and Nutrition Examination Survey (NHANES), 19992016. Logistic regression and linear regression were performed after adjusting for age, sex, race, alcohol consumption, poverty-to-income ratio (PIR), body mass index (BMI), estimated glomerular filtration rate, physical activity, diabetes, cardiovascular disease, and NHANES cycle. Restricted cubic spline models were created to display the potential nonlinear association between SHS and BP levels.

Results: Higher risk of hypertension was found the highest SHS concentrations (OR $=1.13,95 \% \mathrm{Cl} 1.04,1.24, P$ for trend $=0.007$ ). Additionally, SHS exposure had a strong positive association with systolic blood pressure (SBP) but was negatively associated with diastolic blood pressure (DBP). Furthermore, the nonlinear model result showed a significant association between SHS and SBP $(P=0.017)$; however, the nonlinear model result was not significant for SHS or DBP.

Conclusions: Our results suggest a potential association between high SHS exposure and the risk of hypertension. Further research is needed to elucidate the underlying mechanisms.

Keywords: Secondhand smoking, Hypertension, NHANES

\footnotetext{
* Correspondence: pumcwu@sina.com

${ }^{\dagger}$ Qi Zhang and Guowei Zeng contributed equally to the present study and should be regarded as joint first authors.

'Department of Cardiothoracic Surgery, Children's Hospital of Nanjing Medical University, 72 Guangzhou Road, Nanjing 210008, China

Full list of author information is available at the end of the article
}

(c) The Author(s). 2021 Open Access This article is licensed under a Creative Commons Attribution 4.0 International License, which permits use, sharing, adaptation, distribution and reproduction in any medium or format, as long as you give appropriate credit to the original author(s) and the source, provide a link to the Creative Commons licence, and indicate if changes were made. The images or other third party material in this article are included in the article's Creative Commons licence, unless indicated otherwise in a credit line to the material. If material is not included in the article's Creative Commons licence and your intended use is not permitted by statutory regulation or exceeds the permitted use, you will need to obtain permission directly from the copyright holder. To view a copy of this licence, visit http://creativecommons.org/licenses/by/4.0/ The Creative Commons Public Domain Dedication waiver (http://creativecommons.org/publicdomain/zero/1.0/) applies to the data made available in this article, unless otherwise stated in a credit line to the data. 


\section{Introduction}

Hypertension or elevated blood pressure (BP) is defined as systolic blood pressure (SBP) higher than $140 \mathrm{mmHg}$ and/or diastolic blood pressure (DBP) higher than 90 $\mathrm{mmHg}$ [1]. Hypertension is a global health issue that can result in severe consequences, such as cardiovascular disease (CVD), kidney failure, blindness, stroke, and other noncommunicable diseases [2-6]. According to a study analyzing hypertension patients from 90 countries until 2010, 1.39 billion adults aged 20 years or older were estimated to be diagnosed with hypertension, accounting for $31.1 \%$ of the worldwide population [7]. Furthermore, a greater number of hypertension patients was estimated when undiagnosed asymptomatic hypertension and adolescent hypertension were considered [8]. Additionally, the World Health Organization noted that hypertension can be prevented and that its risk factors should receive public attention to promote healthier lifestyle habits [9]. It is widely considered that risk factors for adult hypertension are age, unhealthy diet, tobacco use, physical inactivity, obesity, and others [10]. Environmental factors have also been reported to be nonnegligible factors influencing BP [11, 12], and secondhand smoke (SHS) has been a concern in recent years $[13,14]$.

SHS, or passive smoke, is an environmental pollutant composed of particulate matter generated by tobacco [15]. The reported sites of exposure to SHS are homes, restaurants, workplaces, and bars $[16,17]$. Furthermore, serum cotinine, an assessment of the levels of exposure to nicotine, can also be detected in nonsmokers. A very large number of people suffer from SHS. In Southwest China, more than $70 \%$ of people are exposed to SHS, and most people are reluctant passive smokers [18]. Although tobacco policies have been implemented by various countries, many people are still exposed to SHS, especially in younger, lower income, and lower education groups [19]. Many studies have shown that SHS contributes to numerous diseases, including cancer [20-23], depression [24-26], multiple sclerosis [27], and CVDs [28, 29]. However, there is no definite conclusion about the effect of SHS on hypertension and BP.

Previous epidemiological studies have shown that SHS is associated with hypertension risk $[13,14,30-$ 37], but most of those studies were based on questionnaires, which may be limited by recall bias due to recall error or reporting bias due to subjectivity of the questionnaire survey information. Moreover, it is difficult to quantify SHS exposure via questionnaires, which is another disadvantage. The present study has a larger sample size than previous studies performed to date, including 26,578 participants. Quantitative cotinine data rather than questionnaires were used to assess the degree of SHS exposure. We conducted a stratified analysis and a $P$ interaction analysis to identify sensitive populations with regard to the association of SHS and hypertension. In addition, because SBP and DBP are continuous variables, we further evaluated the nonlinear relationship between serum cotinine levels and SBP and DBP.

\section{Methods \\ Subjects}

Publicly available data were used in our study. Subjects were recruited from nine cycles of the National Health and Nutrition Examination Survey (NHANES) (1999-2000, 20012002, 2003-2004, 2005-2006, 2007-2008, 2009-2010, 2011-2012, 2013-2014, and 2015-2016). The survey design, available data, and methods are detailed on the NHANES website [https://www.cdc.gov/nchs/nhanes/]; NHANES included a sample representative of the noninstitutionalized U.S. population. Biological samples were collected, physical examinations were conducted, and questionnaires were completed in mobile examination centers (MEC).

Subjects who had taken part in the NHANES and whose serum SHS indicator concentrations and BP values were available were recruited. We screened subjects $>15$ years of age in our study who had completed both the NHANES interview and the examination; those who had a smoking history or had missing SHS data were excluded. A total of 25,678 people were included in our study.

\section{Serum cotinine detection}

Cotinine is a major metabolite of nicotine, and the half-life of cotinine is longer than that of nicotine (cotinine, $15-20 \mathrm{~h}$ vs nicotine, $0.5-3 \mathrm{~h}$ ). Therefore, cotinine can be used as a marker of environmental tobacco smoke exposure or "passive smoking." Blood samples were collected at a medical examination center, and the levels of serum cotinine were used to represent the extent of exposure to nicotine, which was measured by isotope dilution high-performance liquid chromatography/atmospheric pressure chemical ionization tandem mass spectrometry (ID HPL-APCI MS/MS). After comparison with the standard curve, the cotinine concentrations were defined according to the ratio of native and labeled cotinine, which is detailed in the NHANES [38]. The distribution of serum cotinine levels is shown in Figure S1.

\section{Outcome assessment}

Three consecutive BP readings were obtained for each participant with a sphygmomanometer by a designated person after the participant rested for at least $5 \mathrm{~min}$. In the present study, we calculated the average of up to 3 brachial systolic (first Korotkoff 
phase) and diastolic (fifth Korotkoff phase) BP readings for every participant [39]. A trained physician evaluated the BP values and measured the value with quality control measures in place. The methods of assessing BP were consistent from 1999 to 2016. Hypertension was defined as one of the following three indicators according to previous studies [40, 41]: First, a mean SBP $\geq 140 \mathrm{~mm} \mathrm{Hg}$ or a mean DBP $\geq 90 \mathrm{~mm} \mathrm{Hg}$. Second, self-reported use of antihypertensive medication. Third, answering yes to the question "Have you ever been told by a doctor or other health care professional that you had hypertension."

\section{Covariate analysis}

Information on physical activity was collected by a self-administered questionnaire. Moderate physical activity was defined as a task that results in slight sweating, a slight increase in breathing, or a slight to moderate increase in heart rate. Strenuous physical activity was defined as a task that results in heavy sweating or a significant increase in breathing or heart rate. Incident diabetes was defined as a self-reported physician diagnosis of diabetes or hemoglobin A1c (HbA1c) level $\geq 6.5 \%$. Incident CVD was defined as any positive self-reported physician diagnosis of congestive heart failure, coronary heart disease, angina pectoris, heart attack, or stroke. All subjects completed the questions related to CVDs in the medical condition questionnaire. The estimated glomerular filtration rate (GFR) is used to reflect kidney function. The calculation formula is as follows: estimated GFR $=175 \times$ standardized Scr ${ }^{-1.154} \times$ age $^{-0.203} \times 1.212$ [if black] $\times 0.742$ [if female], referring to the published literature [42]. Because several factors may influence the outcomes, we selected age (continuous variable), sex (categorical variable, male and female), race (categorical variable, Mexican American, other Hispanic, nonHispanic white, non-Hispanic black and other race including multiracial), alcohol consumption (categorical variable, no and yes), poverty-to-income ratio (PIR, categorical variable, less than 1 and great than or equal to 1 ), body mass index (BMI, categorical variable, less than $25,25-30$, and greater than or equal to 30), estimated GFR (continuous variable), physical activity (categorical variable, none, moderate and vigorous), incident diabetes (categorical variable, no and yes), incident CVD (categorical variable, no and yes), and NHANES cycle (categorical variable) as the covariates in our analysis models. We extracted specific information related to these variables from questionnaires, the NHANES examination data, and laboratory detection data.

\section{Statistical analysis}

For continuous variables, a normal distribution test was carried out. If the variable was normally distributed, a one-way analysis of variance was used for three groups, and an independent samples $t$ test was used for two groups. The Mann-Whitney $U$ test was used for nonnormally distributed variables. We used the chi-square test for categorical variables. We performed logistic regression and general linear regression to explore the association between SHS and hypertension risk and BP levels. We conducted restricted cubic spline (RCS) regression to investigate the nonlinear relationship between SHS and BP levels. A $P$ value less than 0.05 was considered statistically significant. The statistical analyses were carried out with IBM SPSS software, version 20.0 (IBM Corp., Armonk, NY, USA) and R v3.5.0.

\section{Results}

Table 1 shows the baseline characteristics by SHS tertiles. The participants' ages were $46.76 \pm 20.32$ in the lowest SHS group and $37.12 \pm 19.91$ in the highest SHS group. There were more males in the highest SHS exposure group, but fewer females. Subjects who were non-Hispanic black and had a BMI greater than 30 tended to be exposed to more SHS. The highest SHS exposure group had more participants with a family income index PIR of less than 1. Furthermore, a higher number of people in the highest SHS exposure group participated in vigorous physical activity and did not have diabetes. However, fewer people in the highest SHS exposure group drank and suffered from CVD. The serum cotinine levels (ng/ $\mathrm{mL}$ ) of subjects were $0.01 \pm 0,0.03 \pm 0.10$, and 0.67 \pm 1.30 in the low, medium, and high SHS groups, respectively. The proportions of hypertension were $23.9 \%, 28.0 \%$, and $29.5 \%$ in the three groups, respectively.

Table 2 shows that the results of the logistic regression analyses suggested that high SHS exposure was associated with increasing hypertension risk (OR $=1.13,95 \%$ CI $1.04,1.24, P$ for trend $=0.007$ ). In addition, a separate analysis stratified by covariates revealed that subjects who were female, non-Hispanic black, had a PIR greater than 1, with no CVD and no diabetes had the highest SHS exposure and increased hypertension risk, although the $P$ values of the interaction terms were greater than 0.05 . The effects of the OR of other factors are listed in Table S1.

Table 3 indicates that SBP levels tended to be higher (beta $=0.43,95 \%$ CI $0.18,0.67$ ) and $\mathrm{DBP}$ levels tended to be lower (beta $=-0.31,95 \% \mathrm{CI}$ $0.51,-0.12)$ in the highest SHS exposure group. In terms of the association between cotinine and SBP, 
Table 1 Characteristics of the study population by secondhand smoke exposure category from the National Health and Nutrition Examination Survey, 1999-2016

\begin{tabular}{|c|c|c|c|c|c|}
\hline & Total $(n=26578)$ & Tertile $1(n=9038)$ & Tertile $2(n=8779)$ & Tertile $3(n=8761)$ & $P$ value \\
\hline Age (year) & $42.8 \pm 20.6$ & $46.8 \pm 20.3$ & $44.4 \pm 20.4$ & $37.1 \pm 19.9$ & $<0.001$ \\
\hline Sex & & & & & $<0.001$ \\
\hline Male & 10789 (40.6\%) & $3220(35.6 \%)$ & $3628(41.3 \%)$ & 3941 (45.0\%) & \\
\hline Female & 15789 (59.4\%) & $5818(64.4 \%)$ & $5151(58.7 \%)$ & $4820(55.0 \%)$ & \\
\hline Race & & & & & $<0.001$ \\
\hline Mexican American & $6012(22.6 \%)$ & $2280(25.2 \%)$ & $2117(24.1 \%)$ & $1615(18.4 \%)$ & \\
\hline Other Hispanic & $2392(9.0 \%)$ & $1009(11.2 \%)$ & $761(8.7 \%)$ & $622(7.1 \%)$ & \\
\hline Non-Hispanic white & $9828(37.0 \%)$ & $3812(42.2 \%)$ & $3184(36.3 \%)$ & $2832(32.3 \%)$ & \\
\hline Non-Hispanic black & $5709(21.5 \%)$ & $1023(11.3 \%)$ & $1671(19.0 \%)$ & $3015(34.4 \%)$ & \\
\hline Other race-including multiracial & 2637 (9.9\%) & $914(10.1 \%)$ & $1046(11.9 \%)$ & $677(7.8 \%)$ & \\
\hline BMI category (\%) & & & & & $<0.001$ \\
\hline$<25$ & $9373(35.3 \%)$ & $3177(35.2 \%)$ & $3108(35.4 \%)$ & $3088(35.3 \%)$ & \\
\hline $25-30$ & $8556(32.1 \%)$ & $2976(32.9 \%)$ & $2907(33.1 \%)$ & $2673(30.5 \%)$ & \\
\hline$\geq 30$ & 8649 (32.6\%) & $2885(31.9 \%)$ & $2764(31.5 \%)$ & $3000(34.2 \%)$ & \\
\hline Family PIR (\%) & & & & & $<0.001$ \\
\hline$<1$ & $5003(18.8 \%)$ & $1287(14.2 \%)$ & 1464 (16.7\%) & 2252 (25.7\%) & \\
\hline$\geq 1$ & 21575 (81.2\%) & $7751(85.8 \%)$ & 7315 (83.3\%) & 6509 (74.3\%) & \\
\hline Physical activity & & & & & $<0.001$ \\
\hline None & $13672(51.4 \%)$ & $5033(55.7 \%)$ & $4492(51.2 \%)$ & 4147 (47.3\%) & \\
\hline Moderate & 6025 (22.7\%) & $2134(23.6 \%)$ & 2009 (22.9\%) & $1882(21.5 \%)$ & \\
\hline Vigorous & 6635 (25.0\%) & $1810(20.0 \%)$ & $2181(24.8 \%)$ & 2644 (30.2\%) & \\
\hline Missing & $246(0.9 \%)$ & $61(0.7 \%)$ & $97(1.1 \%)$ & $88(1.0 \%)$ & \\
\hline $\begin{array}{l}\text { Estimated glomerular filtration rate } \\
\left(\mathrm{mL} / \mathrm{min} / 1.73 \mathrm{~m}^{2}\right)\end{array}$ & $98.2 \pm 31.5$ & $92.2 \pm 27.6$ & $98.3 \pm 32.4$ & $104.3 \pm 33.2$ & $<0.001$ \\
\hline Diabetes history & & & & & $<0.001$ \\
\hline No & 24025 (90.4\%) & $8054(89.1 \%)$ & 7924 (90.3\%) & 8047 (91.9\%) & \\
\hline Yes & $2548(9.6 \%)$ & $984(10.9 \%)$ & $853(9.7 \%)$ & 711 (8.1\%) & \\
\hline Missing & $5(0.02 \%)$ & $0(0)$ & $2(0.02 \%)$ & $3(0.03 \%)$ & \\
\hline Alcohol consumption & & & & & $<0.001$ \\
\hline No & $8600(32.3 \%)$ & $3291(36.4 \%)$ & $3044(34.7 \%)$ & $2265(25.8 \%)$ & \\
\hline Yes & $11442(43.1 \%)$ & $4103(45.4 \%)$ & $3836(43.7 \%)$ & $3503(40.0 \%)$ & \\
\hline Missing & $6536(24.6 \%)$ & $1644(18.2 \%)$ & 1899 (21.6\%) & $2993(34.2 \%)$ & \\
\hline CVD history & & & & & $<0.001$ \\
\hline No & 19598 (73.7\%) & $7177(79.4 \%)$ & $6742(76.8 \%)$ & $5679(64.8 \%)$ & \\
\hline Yes & $1801(6.8 \%)$ & $658(7.3 \%)$ & $628(7.1 \%)$ & $515(5.9 \%)$ & \\
\hline Missing & $5179(19.5 \%)$ & $1203(13.3 \%)$ & 1409 (16.1\%) & $2567(29.3 \%)$ & \\
\hline NHANES cycle & & & & & $<0.001$ \\
\hline 1999-2000 & $2561(9.6 \%)$ & $0(0)$ & $1346(15.3 \%)$ & 1215 (13.9\%) & \\
\hline $2001-2002$ & $2830(10.7 \%)$ & $836(9.3 \%)$ & $832(9.5 \%)$ & 1162 (13.3\%) & \\
\hline 2003-2004 & $2669(10.0 \%)$ & 741 (8.2\%) & 788 (9.0\%) & 1140 (13.0\%) & \\
\hline 2005-2006 & 2709 (10.2\%) & $769(8.5 \%)$ & 914 (10.4\%) & 1026 (11.7\%) & \\
\hline 2007-2008 & $2983(11.2 \%)$ & 917 (10.2\%) & 1010 (11.5\%) & 1056 (12.1\%) & \\
\hline 2009-2010 & $3306(12.4 \%)$ & $1268(14.0 \%)$ & $1122(12.8 \%)$ & $916(10.5 \%)$ & \\
\hline 2011-2012 & $3042(11.5 \%)$ & $1232(13.6 \%)$ & 1043 (11.9\%) & 767 (8.8\%) & \\
\hline
\end{tabular}


Table 1 Characteristics of the study population by secondhand smoke exposure category from the National Health and Nutrition Examination Survey, 1999-2016 (Continued)

\begin{tabular}{|c|c|c|c|c|c|}
\hline & Total $(n=26578)$ & Tertile $1(n=9038)$ & Tertile $2(n=8779)$ & Tertile $3(n=8761)$ & $P$ value \\
\hline 2013-2014 & $3265(12.3 \%)$ & $1648(18.2 \%)$ & $864(9.8 \%)$ & $753(8.5 \%)$ & \\
\hline 2015-2016 & $3213(12.1 \%)$ & $1627(18.0 \%)$ & $860(9.8 \%)$ & $726(8.2 \%)$ & \\
\hline Serum cotinine level (ng/mL) & $0.2 \pm 0.8$ & $0.01 \pm 0$ & $0.03 \pm 0.10$ & $0.7 \pm 1.3$ & $<0.001$ \\
\hline Hypertension, cases (\%) & $7218(27.2 \%)$ & $2092(23.9 \%)$ & $2459(28.0 \%)$ & $2667(29.5 \%)$ & $<0.001$ \\
\hline Systolic blood pressure (mmHg) & $121.7 \pm 18.9$ & $120.6 \pm 18.2$ & $122.4 \pm 19.6$ & $122.2 \pm 18.6$ & $<0.001$ \\
\hline Diastolic blood pressure $(\mathrm{mmHg})$ & $68.5 \pm 13.0$ & $68.5 \pm 12.4$ & $69.1 \pm 13.2$ & $68.5 \pm 13.3$ & $<0.001$ \\
\hline
\end{tabular}

Tertile 1 , serum cotinine levels $<0.017 \mathrm{ng} / \mathrm{mL}$. Tertile 2 , serum cotinine levels $0.017-0.055 \mathrm{ng} / \mathrm{mL}$. Tertile 3 , serum cotinine levels $\geq 0.055 \mathrm{ng} / \mathrm{mL}$ $B M I$, body mass index; PIR, poverty-to-income ratio; CVD, cardiovascular disease; NHANES, National Health and Nutrition Examination Survey

positive correlations were found for subjects who were female, non-Hispanic black, with a BMI between 25-30, a PIR greater than 1, no exercise or moderate exercise, no diabetes, and no CVD. There was a positive correlation between cotinine and SBP regardless of whether the subject drank or not. For the association of cotinine and DBP, negative correlations were observed for males, Mexican Americans, those with a BMI less than 25 or greater than 30, a PIR greater than 1, no diabetes, and no exercise or vigorous exercise. Figure 1 reveals the continuous associations of SHS exposure with SBP and DBP based on the RCS regression models. A nonlinear association was found between SHS exposure and SBP $(P$ value $=0.017)$, while no association was observed for SHS exposure and DBP $(P$ value $=0.377)$.

\section{Discussion}

For the first time, Alshaarawy et al. used cotinine levels to quantify SHS exposure and found that SHS exposure was associated with hypertension risk and SBP [37]. Our results are consistent with these results: using a larger sample size, we also found that there was a nonlinear relationship between SHS exposure and SBP through RCS analysis. The stratified analysis results showed that women, non-Hispanic black subjects, those with a PIR greater than 1, individuals with no CVD, and individuals with no diabetes were more likely to be exposed to SHS and have high BP, although there was no interaction between SHS and the above factors.

Although some studies also analyzed the relationship between hypertension and SHS [30, 32], our study focused on the association between SHS and BP and included individuals who were considered healthy. Data from the NHANES showed that the level of serum cotinine in people exposed to SHS was approximately 30 times that in those without SHS exposure. In addition, serum cotinine can be a sensitive indicator of the levels of exposure to SHS.
Therefore, in this study, the levels of serum cotinine in nonsmokers represented levels of exposure to SHS instead of the number of cigarettes or hours of exposure per day. Additionally, after excluding those who smoked, 26,578 nonsmokers with SHS exposure were enrolled, without focusing only on one sex or family exposure. Our results provide more objective and rigorous evidence of the relationship between SHS and BP.

Our results found that more women, non-Hispanic black subjects, a PIR greater than 1, those with no CVD, and those with no diabetes were more likely to have SHS exposure and hypertension. There are sex differences in the occurrence of hypertension [43]. Sex differences in BP may also be related to the effect of the hormone environment on long-term $\mathrm{BP}$ regulating systems (such as the renin-angiotensin system in adulthood) [44]. Decreases in estrogen can cause an increase in hypertension in females [45]. It has been reported that exposure to SHS can reduce estrogen in mice [46], which may explain women's susceptibility to SHS and hypertension. Our results also found that non-Hispanic black people are susceptible to secondhand smoking and hypertension, and non-Hispanic black people have been shown to be a high-risk group for hypertension in the American population [47]. In addition, previous studies [48] and our results show that non-Hispanic Black subjects have the highest exposure to SHS. This may explain why non-Hispanic black subjects are susceptible to secondhand smoking and hypertension. The high-income group was also susceptible to SHS and hypertension. There is no mechanismrelated research to support this hypothesis, and more research is needed. Diabetes and CVD are closely related risk factors for hypertension. However, in our study, a stratified analysis of these two diseases revealed that people without diabetes and CVD were susceptible to SHS and hypertension. However, more research is warranted to explain this result. 
Table 2 ORs and 95\% Cl for the associations between secondhand smoke concentrations and hypertension risk in the National Health and Nutrition Examination Survey, 1999-2016

\begin{tabular}{|c|c|c|c|c|c|}
\hline & Tertile 1 & Tertile 2 & Tertile 3 & $P$ for trend & $P$ for interaction \\
\hline Total & Reference & $1.05(0.96,1.13)$ & $1.13(1.04,1.24)$ & 0.007 & \\
\hline Sex & & & & & 0.722 \\
\hline Male & Reference & $1.08(0.95,1.23)$ & $1.11(0.96,1.28)$ & 0.169 & \\
\hline Female & Reference & $1.02(0.92,1.13)$ & $1.16(1.03,1.30)$ & 0.017 & \\
\hline Race & & & & & 0.356 \\
\hline Mexican American & Reference & $0.93(0.77,1.12)$ & $0.97(0.78,1.20)$ & 0.690 & \\
\hline Other Hispanic & Reference & $0.87(0.66,1.15)$ & $1.20(0.88,1.64)$ & 0.404 & \\
\hline Non-Hispanic white & Reference & $1.11(0.98,1.26)$ & $1.14(0.99,1.31)$ & 0.057 & \\
\hline Non-Hispanic black & Reference & $1.23(1.00,1.52)$ & $1.30(1.06,1.59)$ & 0.017 & \\
\hline Other race-including multiracial & Reference & $0.86(0.66,1.11)$ & $0.98(0.72,1.32)$ & 0.780 & \\
\hline BMI category & & & & & 0.549 \\
\hline$<25$ & Reference & $1.02(0.86,1.22)$ & $1.15(0.94,1.41)$ & 0.195 & \\
\hline $25-30$ & Reference & $0.93(0.82,1.07)$ & $1.16(1.00,1.35)$ & 0.067 & \\
\hline$\geq 30$ & Reference & $1.16(1.02,1.32)$ & $1.09(0.96,1.25)$ & 0.200 & \\
\hline Family PIR & & & & & 0.328 \\
\hline$<1$ & Reference & $1.06(0.84,1.32)$ & $1.15(0.92,1.43)$ & 0.217 & \\
\hline$\geq 1$ & Reference & $1.04(0.95,1.14)$ & $1.12(1.01,1.23)$ & 0.028 & \\
\hline Alcohol consumption & & & & & 0.808 \\
\hline No & Reference & $1.02(0.89,1.16)$ & $1.14(0.98,1.31)$ & 0.156 & \\
\hline Yes & Reference & $1.06(0.94,1.19)$ & $1.10(0.96,1.25)$ & 0.093 & \\
\hline CVD history & & & & & 0.288 \\
\hline No & Reference & $1.03(0.94,1.13)$ & $1.12(1.02,1.24)$ & 0.022 & \\
\hline Yes & Reference & $1.13(0.86,1.49)$ & $1.11(0.82,1.50)$ & 0.485 & \\
\hline Diabetes history & & & & & 0.607 \\
\hline No & Reference & $1.04(0.95,1.13)$ & $1.14(1.03,1.25)$ & 0.011 & \\
\hline Yes & Reference & $1.11(0.89,1.39)$ & $1.11(0.87,1.42)$ & 0.370 & \\
\hline Physical activity & & & & & 0.745 \\
\hline None & Reference & $1.03(0.92,1.15)$ & $1.08(0.96,1.22)$ & 0.217 & \\
\hline Moderate & Reference & $1.05(0.89,1.25)$ & $1.20(1.00,1.44)$ & 0.051 & \\
\hline Vigorous & Reference & $1.09(0.89,1.33)$ & $1.22(1.00,1.50)$ & 0.054 & \\
\hline
\end{tabular}

$O R$, odds ratio; $C l$, confidence interval; $B M I$, body mass index; $P I R$, poverty-to-income ratio; $C V D$, cardiovascular disease

The results were obtained after adjusting for age, sex, race, PIR, BMI, physical activity, diabetes, estimated glomerular filtration rate, alcohol consumption, CVD, and NHANES cycle

For the National Health and Nutrition Examination Survey, 1999-2016, the results were obtained after adjusting for all covariates except for the corresponding stratification variable

We also observed a negative association between SHS and DBP. Several studies investigating the relationship between exposure to environmental pollutants (other than SHS) and BP have reported elevated SBP, with no similar increase in DBP in subjects $[49,50]$. However, the exact biological mechanism is unknown. In mice, cigarette smoke exposure can upregulate both SBP and DBP [51-53]. In addition, elevated SBP, but not DBP, was detected in some mice exposed to cigarette smoke [54-56].
Moreover, SBP is more important than DBP for assessing CVD risk [37].

The mechanism by which SHS induces elevated SBP remains unclear, although we still speculated on the possible mechanism based on current studies. Vasodilatation dysfunction, autonomic nervous system imbalance, and vascular aging stimulated by particulates, nicotine, and other components are considered potential mechanisms. First, numerous studies have shown that SHS is involved in the 
Table 3 Multivariable associations of secondhand smoke concentrations with blood pressure from the National Health and Nutrition Examination Survey, 1999-2016

\begin{tabular}{|c|c|c|c|c|}
\hline & \multicolumn{2}{|c|}{ Systolic blood pressure } & \multicolumn{2}{|c|}{ Diastolic blood pressure } \\
\hline & Beta $95 \% \mathrm{Cl}$ & $P$ value & Beta $95 \% \mathrm{Cl}$ & $P$ value \\
\hline Total & $0.43(0.18,0.67)$ & 0.001 & $-0.31(-0.51,-0.12)$ & 0.002 \\
\hline \multicolumn{5}{|l|}{ Sex } \\
\hline Male & $0.16(-0.14,0.47)$ & 0.292 & $-0.39(-0.66,-0.12)$ & 0.004 \\
\hline Female & $0.68(0.31,1.05)$ & $<0.001$ & $-0.16(-0.44,0.12)$ & 0.261 \\
\hline \multicolumn{5}{|l|}{ Race } \\
\hline Mexican American & $0.06(-0.47,0.59)$ & 0.826 & $-0.64(-1.07,-0.21)$ & 0.003 \\
\hline Other Hispanic & $-0.02(-0.84,0.80)$ & 0.970 & $-0.45(-1.08,0.19)$ & 0.169 \\
\hline Non-Hispanic white & $0.38(-0.11,0.87)$ & 0.125 & $-0.23(-0.16,0.14)$ & 0.224 \\
\hline Non-Hispanic black & $0.54(0.14,0.95)$ & 0.009 & $-0.22(-0.56,0.11)$ & 0.195 \\
\hline Other race-including multiracial & $0.62(-0.20,1.43)$ & 0.140 & $-0.31(-0.98,0.36)$ & 0.359 \\
\hline \multicolumn{5}{|l|}{ BMI category } \\
\hline$<25$ & $0.31(-0.02,0.65)$ & 0.065 & $-0.31(-0.60,-0.04)$ & 0.026 \\
\hline $25-30$ & $0.74(0.23,1.25)$ & 0.004 & $-0.09(-0.50,0.32)$ & 0.467 \\
\hline$\geq 30$ & $0.23(-0.23,0.69)$ & 0.324 & $-0.48(-0.84,-0.12)$ & 0.008 \\
\hline \multicolumn{5}{|l|}{ Family PIR } \\
\hline$<1$ & $0.47(0.03,0.91)$ & 0.036 & $-0.09(-0.45,0.27)$ & 0.629 \\
\hline$\geq 1$ & $0.40(0.11,0.69)$ & 0.007 & $-0.39(-0.62,-0.16)$ & 0.001 \\
\hline \multicolumn{5}{|l|}{ Physical activity } \\
\hline None & $0.42(0.05,0.78)$ & 0.027 & $-0.38(-0.67,-0.09)$ & 0.009 \\
\hline Moderate & $0.63(0.04,1.23)$ & 0.037 & $0.11(-0.36,0.57)$ & 0.654 \\
\hline Vigorous & $0.28(-0.07,0.63)$ & 0.118 & $-0.44(-0.74,-0.13)$ & 0.005 \\
\hline \multicolumn{5}{|l|}{ Diabetes history } \\
\hline No & $0.38(0.14,0.61)$ & 0.002 & $-0.34(-0.53,-0.15)$ & 0.001 \\
\hline Yes & $1.63(-0.09,3.36)$ & 0.064 & $0.78(-0.47,2.03)$ & 0.220 \\
\hline \multicolumn{5}{|l|}{ Alcohol consumption } \\
\hline No & $0.72(0.06,1.38)$ & 0.032 & $-0.14(-0.64,0.35)$ & 0.575 \\
\hline Yes & $0.74(0.31,1.18)$ & 0.001 & $-0.19(-0.52,0.15)$ & 0.279 \\
\hline \multicolumn{5}{|l|}{ CVD history } \\
\hline No & $0.80(0.43,1.18)$ & $<0.001$ & $-0.11(-0.40,0.17)$ & 0.437 \\
\hline Yes & $0.63(-1.18,2.45)$ & 0.493 & $-0.82(-2.04,0.39)$ & 0.182 \\
\hline
\end{tabular}

$C l$, confidence interval; $B M I$, body mass index; $P I R$, poverty-to-income ratio; $C V D$, cardiovascular disease

The result was obtained after adjusting for age, sex, race, PIR, BMI, physical activity, diabetes, alcohol consumption, estimated glomerular filtration rate, CVD, and NHANES cycle

regulation of endothelial function [57] and leads to systemic vascular oxidative stress with increasing reactive oxygen species (ROS) and decreasing nitric oxide (NO) [11]. However, it is worth noting that elevated ROS and reduced NO could influence vasodilatation function and further increase BP and pulse pressure [58, 59]. Second, nicotine from SHS could release catecholamine and influence sympatheticvagal balance. Although this stimulation was transient [60], repeated exposure to SHS may result in autonomic nervous system disorder and subsequent vascular remodeling [61, 62], which could increase BP. Third, SHS could also accelerate vascular aging $[63,64]$, which could increase ROS production, decrease biological utilization of $\mathrm{NO}$ and further affect BP.

Some limitations exist in our research. First, although serum cotinine can more precisely reflect the extent of exposure to SHS, other components should also be considered, such as fine particulate matter 


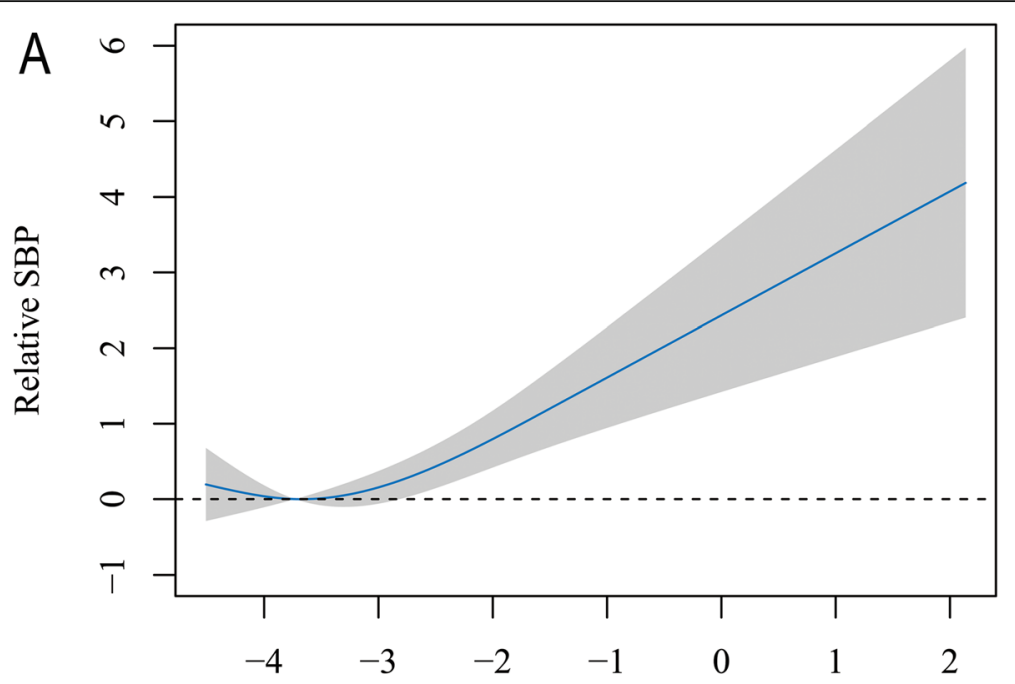

$\log$-transformed Cotinine concentration

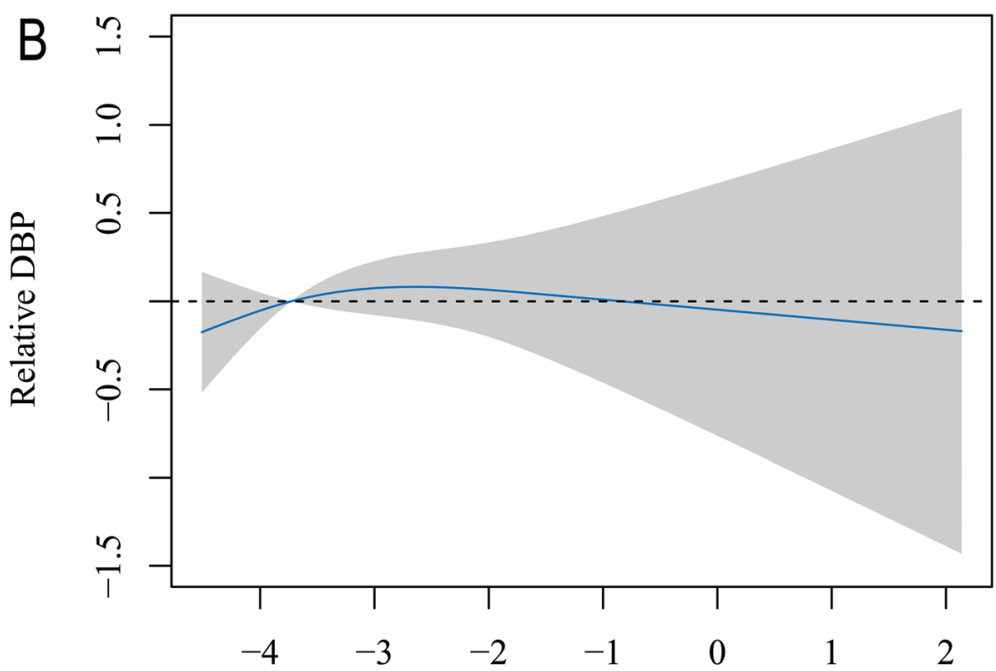

$\log$-transformed Cotinine concentration

Fig. 1 Predicted spline curves for the associations of systolic blood pressure (A) and diastolic blood pressure (B) with secondhand smoke concentrations according to restricted cubic spline regression models

(PM) and acrolein, which are involved in endothelial damage and further affect BP. In addition, the effect of third-hand smoke (THS), which is composed of nicotine along with some novel components and is produced by aging and the accumulation of SHS [65, 66], on BP should also have been considered in our study. However, it was difficult to estimate the influence of THS on BP due to the lack of accurate THS data in NHANES. In addition, genetic susceptibility, such as family history [67, 68], and environmental factors, such as place of residence, can be confounding factors that may affect the association results, but this data was not available in NHANES. However, we cannot ignore the influence of these factors.

\section{Conclusion}

Our study found that a high level of SHS was positively related to increased SBP in adults. The underlying mechanism of SHS-induced hypertension may involve vasodilatation dysfunction, vascular remodeling regulated by the autonomic nervous system, and vascular aging. 


\section{Abbreviations}

BP: Blood pressure; SHS: Secondhand smoke; NHANES: National Health and Nutrition Examination Survey; PIR: Poverty-to-income ratio; BMI: Body mass index; SBP: Systolic blood pressure; DBP: Diastolic blood pressure;

CVD: Cardiovascular disease; MEC: Mobile examination center; ID HPL-APCI MS/MS: Isotope dilution high-performance liquid chromatography/atmospheric pressure chemical ionization tandem mass spectrometry; RCS: Restricted cubic spline; ROS: Reactive oxygen species; NO: Nitric oxide; PM: Particulate matter; THS: Third-hand smoke

\section{Supplementary Information}

The online version contains supplementary material available at https://doi. org/10.1186/s12199-021-01009-0.

Additional file 1: Figure S1. The distribution of serum cotinine levels. Additional file 2: Table S1.

\section{Acknowledgements}

Not applicable.

\section{Authors' contributions}

Conceptualization, writing_original draft: Qi Zhang and Guowei Zeng. Formal analysis: Qi Zhang. Methodology: Xiaowei Wang and Kai-Hong Wu. Data curation, writing - review and editing: all authors. The authors read and approved the final manuscript.

\section{Funding}

This work was supported by funding from the Medical Science and Technology Development Foundation, the Jiangsu Provincial Commission of Health and Family Planning (grant no. ZDRCA2016073), and th Key Project of Jiangsu Commission of Health (ZDA2020004).

\section{Availability of data and materials}

All data generated or analyzed during this study are included in this published article and its supplementary information files.

\section{Declarations}

\section{Ethics approval and consent to participate}

Ethics approval was not required for this research.

\section{Consent for publication}

Not applicable.

\section{Competing interests}

The authors declare that they have no competing interests.

\section{Author details}

'Department of Cardiothoracic Surgery, Children's Hospital of Nanjing Medical University, 72 Guangzhou Road, Nanjing 210008, China. ${ }^{2}$ Department of Cardiovascular Surgery, The First Affiliated Hospital of Nanjing Medical University, Nanjing 210029, China.

Received: 8 June 2021 Accepted: 21 August 2021

Published online: 06 September 2021

\section{References}

1. Verdecchia P, Reboldi G, Angeli F. The 2020 International Society of Hypertension global hypertension practice guidelines - key messages and clinical considerations. Eur J Intern Med. 2020;82:1-6. https://doi.org/10.101 6/j.ejim.2020.09.001.

2. Lamprea-Montealegre JA, Zelnick LR, Hall YN, Bansal N, de Boer $\mid H$. Prevalence of hypertension and cardiovascular risk according to blood pressure thresholds used for diagnosis. Hypertension (Dallas, Tex : 1979), 2018;72(3):602-9. https://doi.org/10.1161/hypertensionaha.118.11609.

3. Hamrahian SM, Falkner B. Hypertension in chronic kidney disease. Adv Exp Med Biol. 2017;956:307-25. https://doi.org/10.1007/5584_2016_84.
4. Kupferman JC, Zafeiriou DI, Lande MB, Kirkham FJ, Pavlakis SG. Stroke and hypertension in children and adolescents. Journal of child neurology. 2017; 32(4):408-17. https://doi.org/10.1177/0883073816685240.

5. Wang $C$, Yuan $Y$, Zheng $M$, Pan A, Wang $M$, Zhao $M$, et al. Association of age of onset of hypertension with cardiovascular diseases and mortality. J Am Coll Cardiol. 2020;75(23):2921-30. https://doi.org/10.101 6/j.jacc.2020.04.038.

6. Bovee DM, Cuevas CA, Zietse R, Danser AHJ, Mirabito Colafella KM, Hoorn EJ. Salt-sensitive hypertension in chronic kidney disease: distal tubular mechanisms. Am J Physiol Renal Physiol. 2020;319(5):F729-F45. https://doi. org/10.1152/ajprenal.00407.2020

7. Mills KT, Stefanescu A, He J. The global epidemiology of hypertension. Nat Rev Nephrol. 2020;16(4):223-37. https://doi.org/10.1038/s41581-019-0244-2.

8. Jackson SL, Zhang Z, Wiltz JL, Loustalot F, Ritchey MD, Goodman AB, et al. Hypertension among youths - United States, 2001-2016. MMWR Morb Mortal Wkly Rep. 2018;67(27):758-62. https://doi.org/10.15585/mmwr. mm6727a2.

9. Whitworth JA, World Health Organization ISoHWG. 2003 World Health Organization (WHO)/International Society of Hypertension (ISH) statement on management of hypertension. Journal Hypertens. 2003;21(11):1983-92. https://doi.org/10.1097/00004872-200311000-00002.

10. Samson R, Ayinapudi K, Le Jemtel TH, Oparil S. Obesity, hypertension, and bariatric surgery. Curr Hypertens Rep. 2020;22(7):46. https://doi.org/10.1007/ s11906-020-01049-x.

11. Munzel T, Sorensen M, Gori T, Schmidt FP, Rao X, Brook FR, et al. Environmental stressors and cardio-metabolic disease: part II-mechanistic insights. Eur Heart J. 2017;38(8):557-64. https://doi.org/10.1093/eurheartj/ ehw294.

12. Alemayehu YA, Asfaw SL, Terfie TA. Exposure to urban particulate matter and its association with human health risks. Environ Sci Pollut Res Int. 2020; 27(22):27491-506. https://doi.org/10.1007/s11356-020-09132-1.

13. Wu L, Yang S, He Y, Liu M, Wang Y, Wang J, et al. Association between passive smoking and hypertension in Chinese non-smoking elderly women. Hypertens Res. 2017:40(4):399-404. https://doi.org/10.1038/hr.2016.162.

14. Park YS, Lee CH, Kim Yl, Ahn CM, Kim JO, Park JH, et al. Association between secondhand smoke exposure and hypertension in never smokers: a crosssectional survey using data from Korean National Health and Nutritional Examination Survey V, 2010-2012. BMJ open. 2018;8(5):e021217. https://doi. org/10.1136/bmjopen-2017-021217.

15. Dobson R, Semple S. "How do you know those particles are from cigarettes?": an algorithm to help differentiate second-hand tobacco smoke from background sources of household fine particulate matter. Environ Res. 2018;166:344-7. https://doi.org/10.1016/j.envres.2018.06.019.

16. Li Z, Yao Y, Yu Y, Shi J, Liu Y, Tao Y, et al. Prevalence and associated factors of passive smoking among women in Jilin Province, China: a cross-sectional study. Int J Environ Res Public Health. 2015;12(11):13970-80. https://doi. org/10.3390/ijerph121113970.

17. Mayne SL, Jacobs DR Jr, Schreiner PJ, Widome R, Gordon-Larsen P, Kershaw $\mathrm{KN}$. Associations of smoke-free policies in restaurants, bars, and workplaces with blood pressure changes in the CARDIA study. J Am Heart Assoc. 2018; 7(23):e009829. https://doi.org/10.1161/jaha.118.009829.

18. Jeong BY, Lim MK, Yun EH, Oh JK, Park EY, Lee DH. Tolerance for and potential indicators of second-hand smoke exposure among nonsmokers: a comparison of self-reported and cotinine verified second-hand smoke exposure based on nationally representative data. Prev Med. 2014;67:280-7. https://doi.org/10.1016/j.ypmed.2014.07.003.

19. Reile R, Parna K. Exposure to second-hand smoke in the context of tobacco policy changes in Estonia, 1996-2016. Eur J Pub Health. 2019;29(4):772-8. https://doi.org/10.1093/eurpub/ckz027.

20. Wilson LF, Antonsson A, Green AC, Jordan SJ, Kendall BJ, Nagle CM, et al. How many cancer cases and deaths are potentially preventable? Estimates for Australia in 2013. Int J Cancer. 2018;142(4):691-701. https://doi.org/10.1 002/ijc.31088.

21. Islami F, Chen W, Yu XQ, Lortet-Tieulent J, Zheng R, Flanders WD, et al. Cancer deaths and cases attributable to lifestyle factors and infections in China, 2013. Ann Oncol. 2017;28(10):2567-74. https://doi.org/10.1093/a nnonc/mdx342.

22. Poirier AE, Ruan $Y$, Grevers $X$, Walter SD, Villeneuve PJ, Friedenreich CM, et al. Estimates of the current and future burden of cancer attributable to active and passive tobacco smoking in Canada. Prev Med. 2019;122:9-19. https://doi.org/10.1016/j.ypmed.2019.03.015. 
23. Xia C, Zheng R, Zeng H, Zhou M, Wang L, Zhang S, et al. Provincial-level cancer burden attributable to active and second-hand smoking in China. Tobacco control. 2018;28(6):669-75. https://doi.org/10.1136/toba ccocontrol-2018-054583.

24. Lange S, Koyanagi A, Rehm J, Roerecke M, Carvalho AF. Association of tobacco use and exposure to second-hand smoke with suicide attempts among adolescents--findings from 33 countries. Nicotine Tob Res. 2019; 22(8):1322-9. https://doi.org/10.1093/ntr/ntz172.

25. Huang J, Xu B, Guo D, Jiang T, Huang W, Liu G, et al. Dose(-)Response relationships between second-hand smoke exposure and depressive symptoms among adolescents in Guangzhou, China. Int J Environ Res Public Health. 2018;15(5):985. https://doi.org/10.3390/ijerph15050985.

26. Ye X, Li L, Gao Y, Zhou S, Yang Y, Chen S. Dose-response relations between second-hand smoke exposure and depressive symptoms among middleaged women. Psychiatry Res. 2015;229(1-2):533-8. https://doi.org/10.1016/j. psychres.2015.06.008.

27. Alphonsus KB, D'Arcy C. Predictors of people's perceptions of second hand smoke exposure as a risk factor for multiple sclerosis. Mult Scler Relat Disord. 2019;36:101383. https://doi.org/10.1016/j.msard.2019.101383.

28. McGorrian C, Yusuf S, Islam S, Jung H, Rangarajan S, Avezum A, et al. Estimating modifiable coronary heart disease risk in multiple regions of the world: the INTERHEART Modifiable Risk Score. Eur Heart J. 2011;32(5):581-9. https://doi.org/10.1093/eurheartj/ehq448.

29. Davis JS, Banfield E, Lee HY, Peng HL, Chang S, Wood AC. Lifestyle behavior patterns and mortality among adults in the NHANES 1988-1994 population: a latent profile analysis. Prev Med. 2019;120:131-9. https://doi.org/10.1016/j. ypmed.2019.01.012.

30. Kim BJ, Kang JG, Kim JH, Seo DC, Sung KC, Kim BS, et al. Association between secondhand smoke exposure and hypertension in 106,268 Korean self-reported never-smokers verified by cotinine. J Clin Med. 2019;8(8):1283. https://doi.org/10.3390/jcm8081238.

31. Tamura T, Kadomatsu Y, Tsukamoto M, Okada R, Sasakabe T, Kawai S, et al. Association of exposure level to passive smoking with hypertension among lifetime nonsmokers in Japan: a cross-sectional study. Medicine. 2018;97(48): e13241. https://doi.org/10.1097/MD.0000000000013241.

32. Yang Y, Liu F, Wang L, Li Q, Wang X, Chen JC, et al. Association of husband smoking with wife's hypertension status in over 5 million Chinese females aged 20 to 49 years. J Am Heart Assoc. 2017;6(3):e004924. https://doi.org/1 $0.1161 / J A H A .116 .004924$

33. Li N, Li Z, Chen S, Yang N, Ren A, Ye R. Effects of passive smoking on hypertension in rural Chinese nonsmoking women. J Hypertens. 2015; 33(11):2210-4. https://doi.org/10.1097/HJH.0000000000000694.

34. Li SJ, Cai L, Shu ZK, Ye YH, Feng R, Cui WL, et al. Analysis of association of economic burden of hypertension with tobacco exposure in Luoping county of Yunnan province. Zhonghua yu fang yi xue za zhi [Chinese journal of preventive medicine]. 2013;47(10):958-62.

35. Seki M, Inoue R, Ohkubo T, Kikuya M, Hara A, Metoki H, et al. Association of environmental tobacco smoke exposure with elevated home blood pressure in Japanese women: the Ohasama study. J Hypertens. 2010;28(9): 1814-20. https://doi.org/10.1097/HJH.0b013e32833a3911.

36. Makris TK, Thomopoulos C, Papadopoulos DP, Bratsas A, Papazachou O, Massias S, et al. Association of passive smoking with masked hypertension in clinically normotensive nonsmokers. Am J Hypertens. 2009;22(8):853-9. https://doi.org/10.1038/ajh.2009.92.

37. Alshaarawy O, Xiao J, Shankar A. Association of serum cotinine levels and hypertension in never smokers. Hypertension. 2013;61(2):304-8. https://doi. org/10.1161/HYPERTENSIONAHA.112.198218.

38. National Center for Health Statistics. NHANES 2003-2004 Laboratory Methods. Cotinine; https://wwwn.cdc.gov/nchs/data/nhanes/2003-2004/la bmethods/l06_c_met_cotinine.pdf. Accessed July 18, 2021.

39. Zhao Q, Shi K, Yang ZG, Diao KY, Xu HY, Liu X, et al. Predictors of aortic dilation in patients with coarctation of the aorta: evaluation with dualsource computed tomography. BMC Cardiovasc Disord. 2018;18(1):124. https://doi.org/10.1186/s12872-018-0863-8

40. Muntner P, Hardy ST, Fine LJ, Jaeger BC, Wozniak G, Levitan EB, et al. Trends in blood pressure control among US Adults with hypertension, 1999-2000 to 2017-2018. Jama. 2020;324(12):1190-200. https://doi.org/10.1001/jama.202 0.14545 .

41. Jackson SL, Cogswell ME, Zhao L, Terry AL, Wang CY, Wright J, et al. Association between urinary sodium and potassium excretion and blood pressure among adults in the United States: National Health and Nutrition
Examination Survey, 2014. Circulation. 2018;137(3):237-46. https://doi.org/1 0.1161/CIRCULATIONAHA.117.029193.

42. Levey AS, Stevens LA, Schmid CH, Zhang YL, Castro AF 3rd, Feldman HI, et al. A new equation to estimate glomerular filtration rate. Ann Intern Med. 2009; 150(9):604-12. https://doi.org/10.7326/0003-4819-150-9-200905050-00006.

43. Gillis EE, Sullivan JC. Sex Differences in hypertension: recent advances. Hypertension. 2016;68(6):1322-7. https://doi.org/10.1161/HYPERTENSIONA HA.116.06602.

44. Ojeda NB, Intapad S, Alexander BT. Sex differences in the developmental programming of hypertension. Acta physiologica. 2014;210(2):307-16. https://doi.org/10.1111/apha.12206.

45. Ojeda NB, Grigore D, Robertson EB, Alexander BT. Estrogen protects against increased blood pressure in postpubertal female growth restricted offspring Hypertension. 2007;50(4):679-85. https://doi.org/10.1161/HYPERTENSIONA HA.107.091785.

46. Santucci-Pereira J, Pogash TJ, Patel A, Hundal N, Barton M, Camoirano A, et al. Aspirin abrogates impairment of mammary gland differentiation induced by early in life second-hand smoke in mice. Carcinogenesis. 2018; 39(8):1037-44. https://doi.org/10.1093/carcin/bgy064.

47. Ferdinand KC, Nasser SA. Management of Essential Hypertension. Cardiol Clin. 2017;35(2):231-46. https://doi.org/10.1016/j.ccl.2016.12.005.

48. Tsai J, Homa DM, Gentzke AS, Mahoney M, Sharapova SR, Sosnoff CS, et al. Exposure to Secondhand Smoke Among Nonsmokers - United States, 1988 2014. MMWR Morb Mortal Wkly Rep. 2018;67(48):1342-6. https://doi.org/10.1 5585/mmwr.mm6748a3.

49. Cosselman KE, Krishnan RM, Oron AP, Jansen K, Peretz A, Sullivan JH, et al Blood pressure response to controlled diesel exhaust exposure in human subjects. Hypertension. 2012;59(5):943-8. https://doi.org/10.1161/ HYPERTENSIONAHA.111.186593.

50. Sun Q, Hong X, Wold LE. Cardiovascular effects of ambient particulate air pollution exposure. Circulation. 2010;121(25):2755-65. https://doi.org/10.11 61/CIRCULATIONAHA.109.893461.

51. Talukder MA, Johnson WM, Varadharaj S, Lian J, Kearns PN, El-Mahdy MA, et al. Chronic cigarette smoking causes hypertension, increased oxidative stress, impaired NO bioavailability, endothelial dysfunction, and cardiac remodeling in mice. Am J Physiol Heart Circ Physiol. 2011;300(1):H388-96. https://doi.org/10.1152/ajpheart.00868.2010.

52. El-Mahdy MA, Abdelghany TM, Hemann C, Ewees MG, Mahgoup EM, Eid MS, et al. Chronic cigarette smoke exposure triggers a vicious cycle of leukocyte and endothelial-mediated oxidant stress that results in vascular dysfunction. Am J Physiol Heart Circ Physiol. 2020;319(1):H51-65. https://doi. org/10.1152/ajpheart.00657.2019.

53. Oakes JM, Xu J, Morris TM, Fried ND, Pearson CS, Lobell TD, et al. Effects of Chronic Nicotine Inhalation on Systemic and Pulmonary Blood Pressure and Right Ventricular Remodeling in Mice. Hypertension. 2020;75(5):1305-14. https://doi.org/10.1161/HYPERTENSIONAHA.119.14608.

54. Nemmar A, Al-Salam S, Yuvaraju P, Beegam S, Yasin J, Ali BH. Chronic exposure to water-pipe smoke induces cardiovascular dysfunction in mice. Am J Physiol Heart Circ Physiol. 2017;312(2):H329-H39. https://doi.org/10.11 52/ajpheart.00450.2016.

55. Vanderstocken G, Marrow JP, Allwood MA, Stampfli MR, Simpson JA. Disruption of Physiological Rhythms Persist Following Cessation of Cigarette Smoke Exposure in Mice. Front Physiol. 2020;11:501383. https://doi.org/10.33 89/fphys.2020.501383.

56. Nemmar A, Al-Salam S, Beegam S, Yuvaraju P, Ali BH. Gum arabic ameliorates impaired coagulation and cardiotoxicity induced by water-pipe smoke exposure in mice. Front Physiol. 2019;10:53. https://doi.org/10.3389/ fphys.2019.00053.

57. Konukoglu D, Uzun H. Endothelial dysfunction and hypertension. Adv Exp Med Biol. 2017;956:511-40. https://doi.org/10.1007/5584_2016_90.

58. Higashi $Y$, Kihara $Y$, Noma K. Endothelial dysfunction and hypertension in aging. Hypertens Res. 2012;35(11):1039-47. https://doi.org/10.1038/hr.2 012.138.

59. Brandes RP. Endothelial dysfunction and hypertension. Hypertension (Dallas, Tex : 1979). 2014;64(5):924-8. https://doi.org/10.1161/ hypertensionaha.114.03575.

60. Kokubo Y, Padmanabhan S. Necessity of preventing cardiovascular disease by smoke-free policies. J Am Heart Assoc. 2018;7(23):e011120. https://doi. org/10.1161/jaha.118.011120.

61. Yu AR, Hasjim B, Yu LE, Gabriel C, Anshus A, Lee JB, et al. Comparison of ultrasound-measured properties of the common carotid artery to tobacco 
smoke exposure in a cohort of Indonesian patients. World J Emerg Med. 2017;8(3):177-83. https://doi.org/10.5847/wjem.j.1920-8642.2017.03.003.

62. Raghuveer G, White DA, Hayman LL, Woo JG, Villafane J, Celermajer D, et al. Cardiovascular consequences of childhood secondhand tobacco smoke exposure: prevailing evidence, burden, and racial and socioeconomic disparities: a scientific statement from the American Heart Association. Circulation. 2016;134(16):e336-e59. https://doi.org/10.1161/cir. 0000000000000443 .

63. Wei J, Shufelt C, Oestreicher Stock E, Mills C, Dhawan S, Jacob R, et al. Vascular aging is accelerated in flight attendants with occupational secondhand smoke exposure. J Occup Environ Med. 2019;61(3):197-202. https://doi.org/10.1097/jom.0000000000001497.

64. Lu L, Johnman C, McGlynn L, Mackay DF, Shiels PG, Pell JP. Association between exposure to second-hand smoke and telomere length: crosssectional study of 1303 non-smokers. Int J Epidemiol. 2017;46(6):1978-84. https://doi.org/10.1093/ije/dyx212.

65. Chen Y, Adhami N, Martins-Green M. Biological markers of harm can be detected in mice exposed for two months to low doses of third hand smoke under conditions that mimic human exposure. Food Chem Toxicol. 2018;122:95-103. https://doi.org/10.1016/.jfct.2018.09.048.

66. Kuo HW, Rees WW. Third-hand smoke (THS): What is it and what should we do about it? J Formos Med Assoc. 2019;118(11):1478-9. https://doi.org/10.1 016/j.jfma.2019.08.025.

67. Zhao Q, Miljkovic I. Weight Loss and Blood pressure changes, roles played by genetic susceptibility and macronutrients. Hypertension (Dallas, Tex : 1979). 2019:74(6):1300-1. https://doi.org/10.1161/hypertensionaha.119.13677.

68. Sun D, Zhou T, Li X, Heianza Y, Liang Z, Bray GA, et al. Genetic susceptibility, dietary protein intake, and changes of blood pressure: the POUNDS Lost Trial. Hypertension (Dallas, Tex : 1979). 2019;74(6):1460-7. https://doi.org/1 0.1161 /hypertensionaha.119.13510.

\section{Publisher's Note}

Springer Nature remains neutral with regard to jurisdictional claims in published maps and institutional affiliations.

Ready to submit your research? Choose BMC and benefit from:

- fast, convenient online submission

- thorough peer review by experienced researchers in your field

- rapid publication on acceptance

- support for research data, including large and complex data types

- gold Open Access which fosters wider collaboration and increased citations

- maximum visibility for your research: over $100 \mathrm{M}$ website views per year

At $\mathrm{BMC}$, research is always in progress.

Learn more biomedcentral.com/submissions 